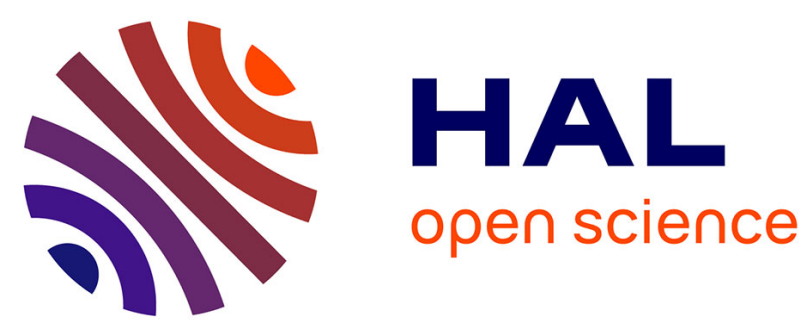

\title{
Radar Observation of Extreme Vertical Drafts in the Polar Summer Mesosphere
}

J. Chau, R. Marino, F. Feraco, J. Urco, G. Baumgarten, F.-j. Lübken, W. Hocking, C. Schult, T. Renkwitz, R. Latteck

\section{- To cite this version:}

J. Chau, R. Marino, F. Feraco, J. Urco, G. Baumgarten, et al.. Radar Observation of Extreme Vertical Drafts in the Polar Summer Mesosphere. Geophysical Research Letters, 2021, 48 (16), 10.1029/2021GL094918 . hal-03451852

\section{HAL Id: hal-03451852 \\ https://hal.science/hal-03451852}

Submitted on 27 Nov 2021

HAL is a multi-disciplinary open access archive for the deposit and dissemination of scientific research documents, whether they are published or not. The documents may come from teaching and research institutions in France or abroad, or from public or private research centers.
L'archive ouverte pluridisciplinaire HAL, est destinée au dépôt et à la diffusion de documents scientifiques de niveau recherche, publiés ou non, émanant des établissements d'enseignement et de recherche français ou étrangers, des laboratoires publics ou privés. 


\section{Geophysical Research Letters}

\author{
RESEARCH LETTER \\ 10.1029/2021GL094918 \\ Key Points: \\ - First observations of extreme vertical \\ velocities in the polar summer \\ mesosphere \\ - The observed solitary wave in \\ a varicose mode resembles a \\ mesospheric bore, with large vertical \\ extent and vertical velocities \\ - Such extreme events might have \\ been missed or ignored in previous \\ observations of vertical velocities or \\ other mesospheric observations
}

Supporting Information:

Supporting Information may be found in the online version of this article.

Correspondence

J. L. Chau,

chau@iap-kborn.de

Citation:

Chau, J. L., Marino, R., Feraco, F., Urco, J. M., Baumgarten, G., Lübken, F.-J., et al. (2021). Radar observation of extreme vertical drafts in the polar summer mesosphere. Geophysical Research Letters, 48, e2021GL094918. https://doi.org/10.1029/2021GL094918

Received 23 JUN 2021

Accepted 22 JUL 2021 (c) 2021. The Authors.

This is an open access article under the terms of the Creative Commons Attribution-NonCommercial-NoDerivs License, which permits use and distribution in any medium, provided the original work is properly cited, the use is non-commercial and no modifications or adaptations are made.

\section{Radar Observation of Extreme Vertical Drafts in the Polar Summer Mesosphere}

\author{
J. L. Chau' ${ }^{1}$, , R. Marino ${ }^{2}$, F. Feraco ${ }^{2,3}$, J. M. Urco ${ }^{1,4}$, G. Baumgarten ${ }^{1}$, F.-J. Lübken ${ }^{1}$ (), \\ W. K. Hocking ${ }^{5}$, C. Schult ${ }^{1}$, T. Renkwitz ${ }^{1}$, and R. Latteck ${ }^{1}$ (D) \\ ${ }^{1}$ Leibniz-Institute of Atmospheric Physics at the University of Rostock, Kühlungsborn, Germany, ${ }^{2}$ Laboratoire de \\ Mécanique des Fluides et d'Acoustique, CNRS, École Centrale de Lyon, Université Claude Bernard Lyon 1, INSA de \\ Lyon, Écully, France, ${ }^{3}$ Dipartimento di Fisica, Universitá della Calabria, Rende, Italy, ${ }^{4}$ Department of Electrical and \\ Computer Engineering and Coordinated Science Laboratory, University of Illinois Urbana-Champaign, Urbana, IL, \\ USA, ${ }^{5}$ Department of Physics and Astronomy, University of Western Ontario, London, ON, Canada
}

\begin{abstract}
The polar summer mesosphere is the Earth's coldest region, allowing the formation of mesospheric ice clouds. These ice clouds produce strong polar mesospheric summer echoes (PMSE) that are used as tracers of mesospheric dynamics. Here, we report the first observations of extreme vertical drafts $\left( \pm 50 \mathrm{~ms}^{-1}\right)$ in the mesosphere obtained from PMSE, characterized by velocities more than five standard deviations larger than the observed vertical wind variability. Using aperture synthesis radar imaging, the observed PMSE morphology resembles a solitary wave in a varicose mode, narrow along propagation $(3-4 \mathrm{~km})$ and elongated $(>10 \mathrm{~km})$ transverse to propagation direction, with a relatively large vertical extent $(\sim 13 \mathrm{~km})$. These spatial features are similar to previously observed mesospheric bores, but we observe only one crest with much larger vertical extent and higher vertical velocities.
\end{abstract}

Plain Language Summary Extreme events are ubiquitous in geophysical flows. Examples of these events are tornadoes and rogue waves in the lower atmosphere and oceans, respectively. In the mesosphere, the boundary of Earth's atmosphere and outer space, extreme events can also occur, although this region is poorly observed. Here, we present the first observations of extreme vertical velocities $\left( \pm 50 \mathrm{~ms}^{-1}\right)$ in the mesosphere, that are more than five times their expected standard deviation. These observations are possible by tracking and imaging strong mesospheric radar echoes that occur in the summer at polar latitudes, with a radar used in a radio camera mode. The morphology of our observations resembles previously observed instabilities called bores or wave walls, but with much larger vertical velocities and vertical extents.

\section{Introduction}

Extreme events are ubiquitous in geophysical flows, for example, tornadoes or rogue waves (e.g., Adcock \& Taylor, 2014; Tippett \& Cohen, 2016). In the mesosphere (60-90 km), extreme events can also exist. This region is difficult to observe since it is too high for meteorological balloons, and too low for satellites to fly through and make in situ measurements. Therefore, observations of extreme events and their respective impacts in this region are not easy to identify and study. Nonetheless, this atmospheric region hosts a number of interesting optical and radio phenomena like noctilucent clouds (NLCs) and polar mesospheric summer echoes (PMSE) (e.g., Ecklund \& Balsley, 1981; Hoppe et al., 1988; Thomas \& Olivero, 1986).

During summer months at mid and high latitudes, the mesosphere is the coldest place on Earth with temperatures as low as $130 \mathrm{~K}$ due to dynamical processes that drive the atmosphere away from a radiatively controlled state (e.g., Lübken et al., 1999). One of the most challenging, important, and intriguing mesospheric measurements is vertical winds. Vertical winds are usually smaller than horizontal winds, but they have significant effects on the atmospheric dynamics, composition, electrodynamics, and mixing (e.g., Larsen \& Meriwether, 2012; Pouquet et al., 2017). Their mean synoptic-scale values are expected to be in the order of centimeters per second and are difficult to measure directly (e.g., Gudadze et al., 2019). On the other hand measurements made with ground-based radars, passive optics, lidars, as well as in situ chemical traces, show high values varying by up to $\pm 10 \mathrm{~ms}^{-1}$ (e.g., Gardner \& Liu, 2007; Hoppe \& Fritts, 1995; Lehmacher et al., 2011; Woodman \& Guillén, 1974). Similar and even higher values have been observed at 
higher altitudes in the thermosphere (e.g., Larsen \& Meriwether, 2012). These high values can occur with the same sign for minutes to hours.

Although part of this variability is attributed to Kelvin-Helmholtz, mesospheric bores, and other instabilities (e.g., Chau et al., 2020), the drivers for the majority of observations of large and/or persistent values are not obvious. Waves propagating through the region appear to be connected to the vertical wind variability; either they come from below or are generated locally via instabilities, nonlinear interaction with other waves or turbulence (e.g., Fritts et al., 2004; Gardner et al., 1995; Herbert et al., 2016; Larsen \& Meriwether, 2012). Moreover, high variability in vertical winds has been reproduced in direct numerical simulations (DNS) in flows similar to those in the mesosphere (Marino et al., 2015), including extreme values in a certain range of the governing parameters of the flow (Feraco et al., 2018). Understanding and characterizing the vertical wind variability of the mesosphere and higher altitudes (thermosphere) are important for explaining their effects on the dynamics, composition, chemistry, and electrodynamics of these regions (e.g., Larsen \& Meriwether, 2012).

In this study, we focus on extreme vertical drafts observed in the polar summer mesosphere. These observations have been made with the Middle Atmosphere Alomar Radar System (MAARSY) located in northern Norway $\left(69.30^{\circ} \mathrm{N}, 16.04^{\circ} \mathrm{E}\right)$. Observations of PMSE have been routinely made with MAARSY since 2010 (Latteck et al., 2012). After more than 20 years of active research, the physics behind PMSE is well understood. Their signal strength depends on electron density, turbulence, and charged-ice particles (e.g., Rapp \& Lübken, 2004) and they are good tracers of atmospheric winds (e.g., Sato et al., 2017).

The event we present is extreme as the vertical velocities measured are more than five times the standard deviation $\left(\sigma_{w}\right)$ of continuous measurements over two summers. The paper is structured as follows: Section 2 describes the observing modes and Section 3 presents the observations. These observations and possible connections to previously observed mesospheric instabilities are discussed in Section 4.

\section{Radar Observing Modes}

MAARSY is an active phased array that consists of 433 three-element cross-polarized Yagi antennas and operates at $53.5 \mathrm{MHz}$. Its main beam one-way half-power beam-width is $4^{\circ}$. On reception, either all 433 elements, or up to seven groups of 49 elements, or up to 15 out of 55 groups of seven elements can be used (e.g., Latteck et al., 2012, for more details).

PMSE are routinely observed with MAARSY using two quasi-simultaneous main modes: (a) multi-beam, and (b) radar imaging (e.g., Gudadze et al., 2019; Urco et al., 2019). These modes have been used during the summers of 2016 and 2017, except for a few days where other modes were used to support special requests. Both modes run with $1 \mathrm{~ms}$ interpulse period. Since horizontal winds are expected to be within $\pm 150 \mathrm{~ms}^{-1}$, the multi-beam mode has been configured to allow a Nyquist velocity of $\pm 35 \mathrm{~ms}^{-1}$. On the other hand, the radar imaging mode allows a Nyquist velocity of $\pm 175 \mathrm{~ms}^{-1}$, suitable to study other echoes, for example, nonspecular meteor echoes (Chau et al., 2014).

Given the velocity aliasing in the multi-beam mode, in this work we use only data from the radar imaging mode, which observes for $30 \mathrm{~s}$ every $180 \mathrm{~s}$. This mode uses only one vertically pointing transmitting beam using all 433 elements, while 16 antenna groups are used on reception, 15 of them for radar imaging. A spectral moment method has been implemented to obtain: signal, mean radial velocity, and spectral width. Radial velocities from slightly off-vertical locations could have contributions from horizontal velocities. However, unrealistic supersonic horizontal winds (more than $1,500 \mathrm{~ms}^{-1}$ ) would be required to generate the large $\left(\sim 50 \mathrm{~ms}^{-1}\right)$ observed velocities.

Radar imaging has been obtained by applying the Maximum Entropy method on the cross-spectral data from combinations of receiving antenna pairs (e.g., Hysell \& Chau, 2006; Urco et al., 2019). Since the selected 15 receiving antennas do not have the same beam width, the imaging inversion has been performed only within $\pm 8^{\circ}$ zenith angles. This angular coverage also allows for the observation of PMSE outside the main illuminated area, if strong echoes are present there. 


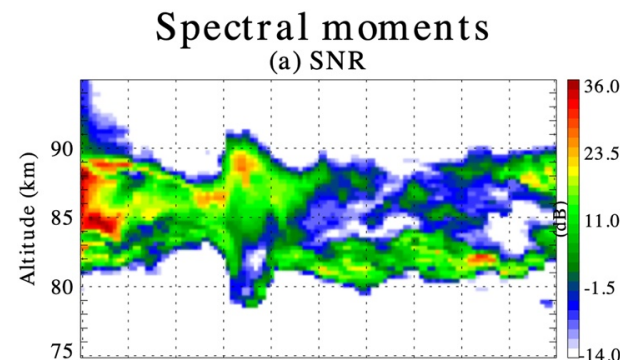

(b) Vertical velocity (+ve upward)

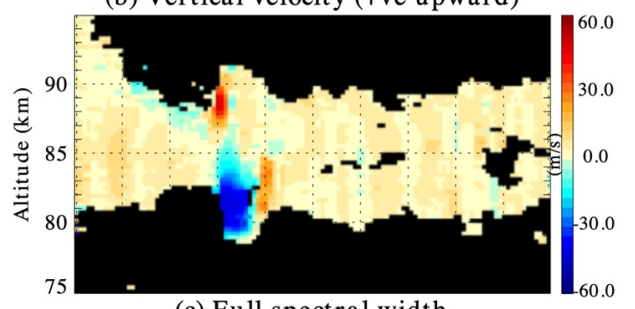

(c) Full spectral width

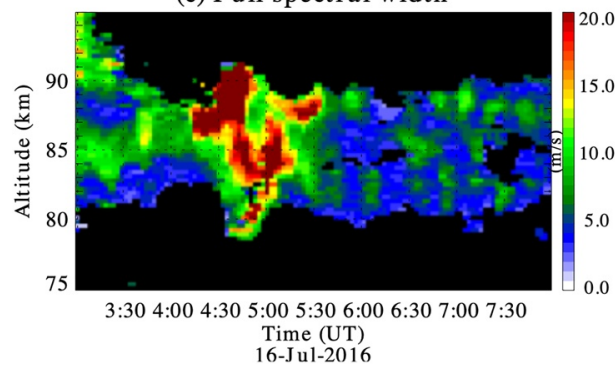

Selected spectra (+ve upward)

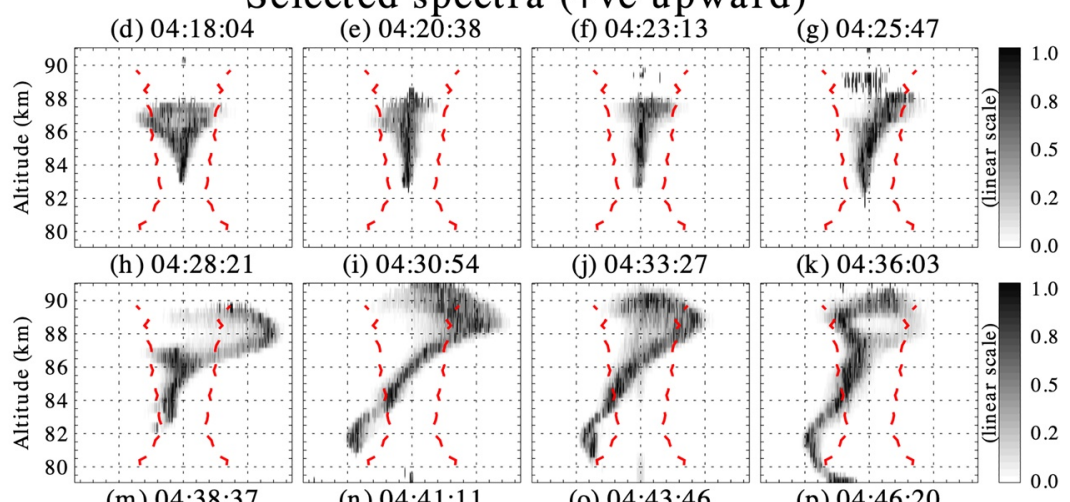

(o) $04: 43: 46$ (n) $04: 41: 11$ (p) 04:46:20

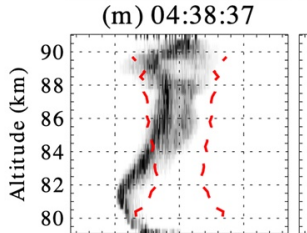

(q) 04:48:54

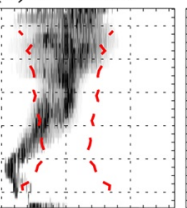

(r) $04: 51: 28$

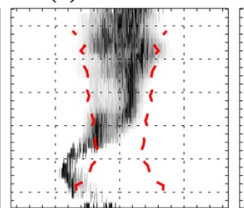

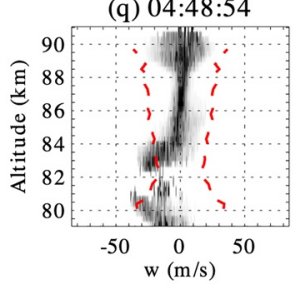
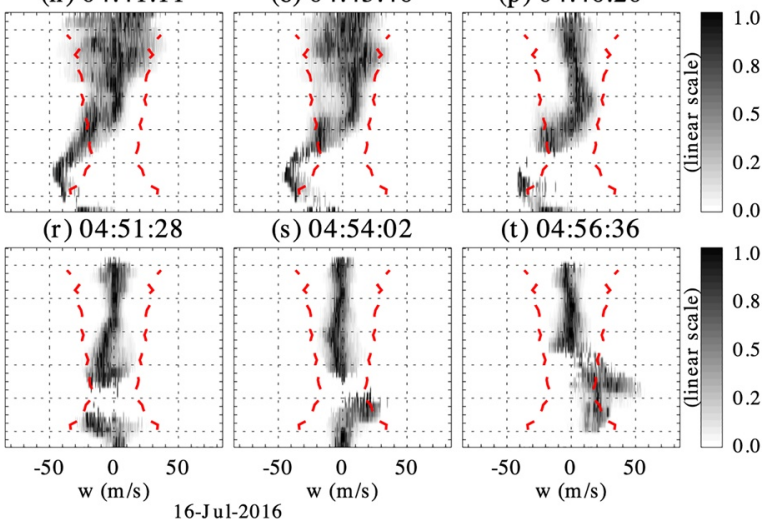

(t) $04: 56: 36$

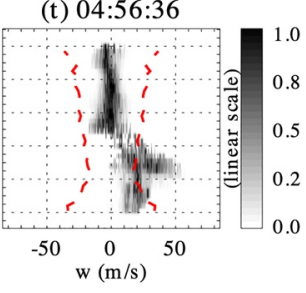

Figure 1. (left) Range-time plots of: (a) signal-to-noise ratio (SNR), (b) vertical velocity (positive upward), and (c) total spectral width, observed with a vertical pointing beam on July 16,2016 . Note the relative large scales being shown for vertical velocities $\left( \pm 60 \mathrm{~ms}^{-1}\right)$. (right) Normalized spectra as a function of $w$, where $w=-f \lambda / 2, f$ is Doppler frequency in $\mathrm{Hz}$, and $\lambda$ the radar wavelength in meters. The normalization is in power spectra amplitude for each altitude with respect to its maximum. Three-sigma levels $\left(3 \sigma_{w}\right)$ based on June-July 2016 observations are plotted in dashed red lines.

Besides the PMSE observations, in this work we also used the horizontal wind observations with a specular meteor radar (SMR) located also in Andoya (e.g., Chau et al., 2017). This system consists of one single element Yagi antenna on transmission and five single element antennas on reception arranged in an interferometer configuration. On reception echoes from meteor trails perpendicular to the line of sight are detected and identified. The radial velocity and location (range and angle) of each meteor trail within selected altitude and temporal bins are used to estimate a mean horizontal wind vector for that bin (e.g., Hocking et al., 2001). Such vector components are obtained assuming a homogeneous wind inside the illuminated area, that is, a circle of approximately $400 \mathrm{~km}$ diameter at $86 \mathrm{~km}$ altitude.

\section{Results}

The extreme vertical draft event occurs on July 16, 2016 and is shown in Figures 1a-1c. Figure 1a shows the signal-to-noise ratio (SNR) as a function of altitude and time. The vertical velocities and spectral widths are shown in Figures $1 \mathrm{~b}$ and 1c, respectively.

The event in question occurred between 04:25 and 05:00 universal time (UT) and is characterized by: (a) episodes of large vertical updrafts and downdrafts lasting a few minutes at around $86 \mathrm{~km}$, (b) large spectral widths, and (c) echoes appearing to move up and down according to the measured mean vertical velocities, and (d) their strength increasing (decreasing) when going up (down). Outside this time interval, the PMSE spectral moments behave within expected values, that is, vertical velocities within $\pm 5 \mathrm{~ms}^{-1}$, spectral widths below $5 \mathrm{~ms}^{-1}$, and echoes occurring in multiple layers.

Normalized spectrograms for selected times around the extreme event are shown in Figures 1d-1t. Each spectrum is obtained from $\sim 30 \mathrm{~s}$ continuous observations. The striking features in this figure are the large 


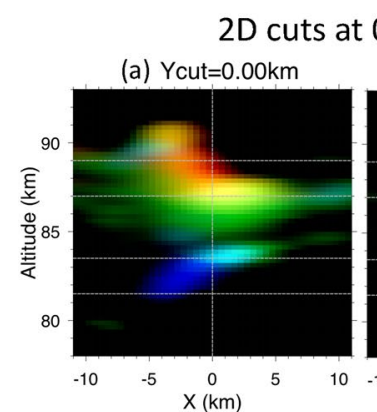

(c) Zcut $=89.00 \mathrm{~km}$

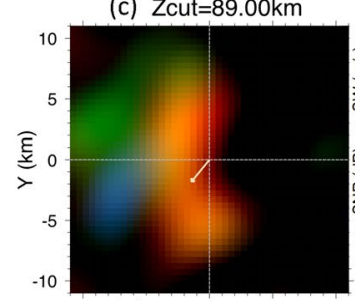

(e) Zcut $=83.50 \mathrm{~km}$

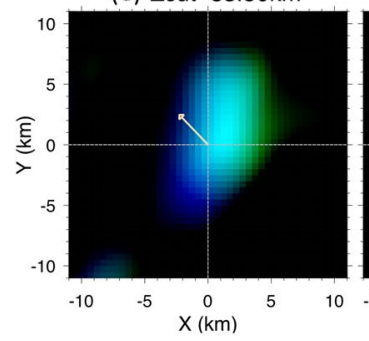

(b) Xcut $=0.00 \mathrm{~km}$

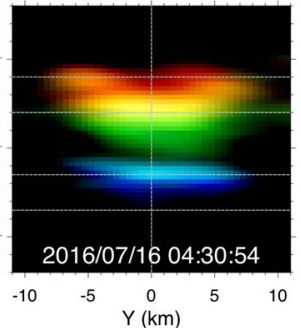

(d)

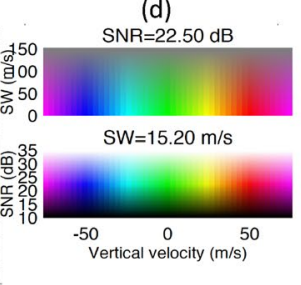

(f) Zcut $=81.50 \mathrm{~km}$

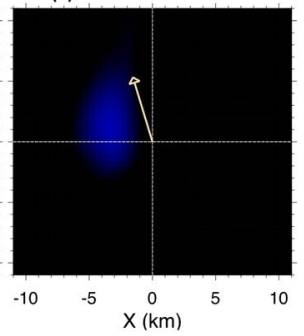

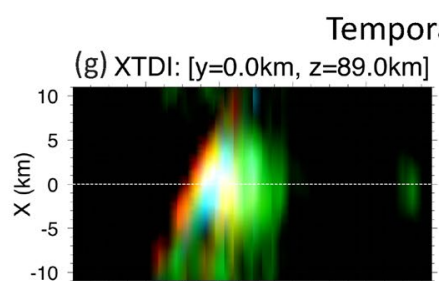

(h) XTDI: [y=0.0km, $z=87.0 \mathrm{~km}]$

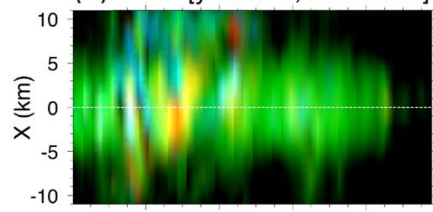

(i) XTDI: [y=0.0km, z=83.5km]

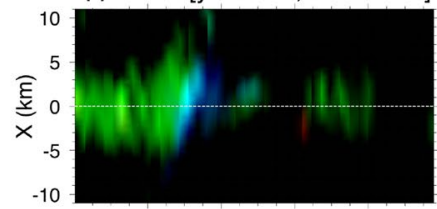

(j) XTDI: [y=0.0km, $z=81.5 \mathrm{~km}]$

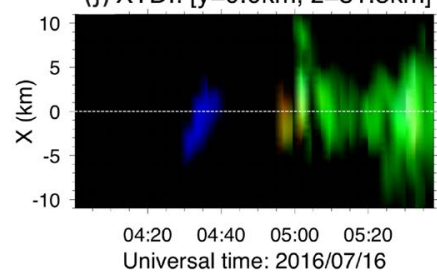

evolution

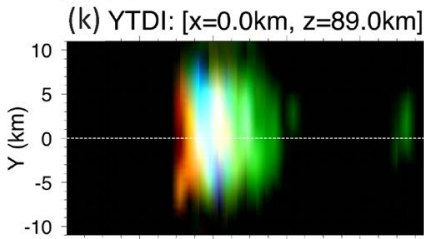

(I) YTDI: $[x=0.0 \mathrm{~km}, z=87.0 \mathrm{~km}]$

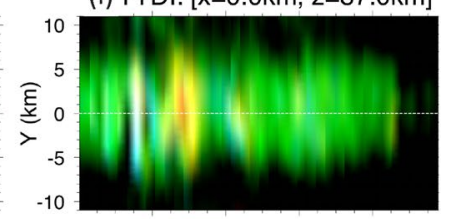

(m) YTDI: $[x=0.0 \mathrm{~km}, z=83.5 \mathrm{~km}]$

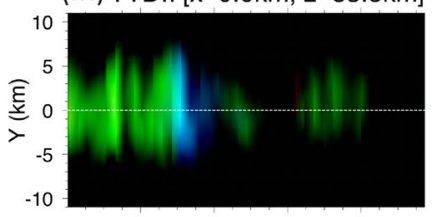

(n) YTDI: $[x=0.0 \mathrm{~km}, z=81.5 \mathrm{~km}]$

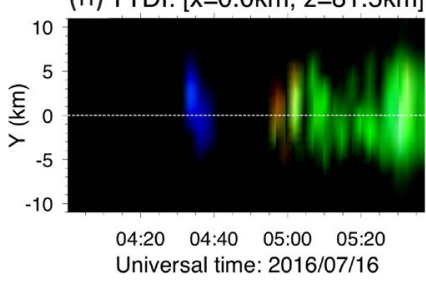

Figure 2. (left) Two dimensional spatial cuts of polar mesospheric summer echoes inside the illuminated volume on July 16, 2016 around 04:30 UT. $x z$ and $y z$ cuts at $x=0$ and $y=0 \mathrm{~km}$ in panels (a) and (b), respectively. $x y$ cuts at altitudes $89.0,83.5$, and $81.5 \mathrm{~km}$ in panels (c), (e), and (f), respectively. The intensity indicates signal strength of the echoes, while the color shows vertical velocity. Red (blue) values represent upward (downward) velocities greater (smaller) than $25(-25) \mathrm{ms}^{-1}$, while green values represent velocities in between (see panel d). The 30-min horizontal wind from the specular meteor radar is indicated with a yellow arrow in the center of each $x y$ cut. (right) Space-time cuts at altitudes 89.0, 87.0, 83.5, and $81.5 \mathrm{~km}$, of $x y$ cuts in the left panel: (g-j) $x$ versus time for $y=0$, and $(\mathrm{k}-\mathrm{n}) y$ versus time for $x=0$.

positive and negative vertical drafts well outside $3 \sigma_{w}$, reaching high absolute values (e.g., $65 \mathrm{~ms}^{-1}$ at 04:28:21 UT or $-45 \mathrm{~ms}^{-1}$ at 04:36:03 UT). Except for the spectra at 04:41:11 (10) and 04:43:46 (1n) UT, the spectra are composed of one or two velocity peaks at a given altitude. Given that the illuminated volume has a radius of about $5 \mathrm{~km}$ in the horizontal direction at these altitudes, the multi-peak features are a result of multiple regions of enhanced backscattering within the illuminated volume. The presence of multiple peaks gives rise to large values of spectral widths. The red dashed lines indicate the $3 \sigma_{w}$ based on 2 months of continuous observations in 2016.

From radar imaging, we have obtained spatial information of features within the illuminated volume. Figures 2a-2f show selected 2D spatial planes of imaging around 04:30:54 UT. The large-scale 30-min averaged horizontal winds obtained from a closely located SMR are shown in arrows as a reference. Radar imaging results clearly indicate that the extreme updrafts and downdrafts are localized in horizontal space, with 3-4 km width along the $x$ axis, and at least 8-12 km elongation along the $y$ axis, where $x$-axis and $y$-axis are rotated $50^{\circ}$ East of North. Note that the elongation along $y$ axis could be larger but our observations are limited to the radar illuminated area. An animation of similar frames from 04:00 to 05:30 UT every 150-170 s can be seen in Movie S1. The imaging results are also used to verify that the inferred vertical velocities are mainly due to vertical wind and not to a horizontal wind contamination, since areas of large vertical drafts are observed at or close to overhead inside the vertical transmitting beam. For typical mesospheric horizontal winds $\left( \pm 150 \mathrm{~ms}^{-1}\right)$, their contamination in our vertical estimates would be at most within $\pm 4 \mathrm{~ms}^{-1}$. 
(a) U Mag.
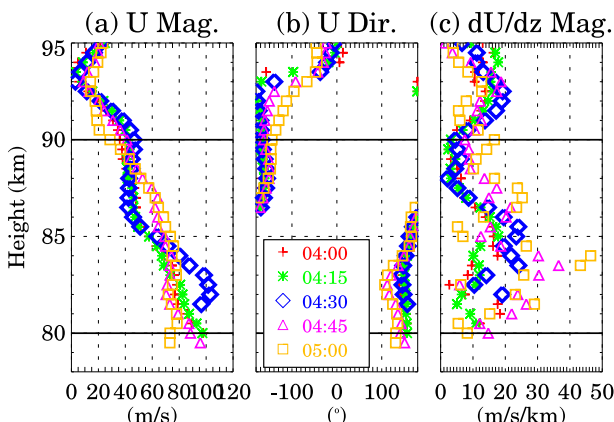

01020304050

Figure 3. Horizontal winds profiles obtained with a collocated radar that observe specular meteor echoes around 04:30 UT on July 16, 2016: horizontal wind magnitude and direction with their respective vertical gradients. The direction is with respect to $x$, positive anti-clockwise. The colors indicate time in minutes with respect to 04:30 UT. The central time values are marked with black diamonds. $(\mathrm{m} / \mathrm{s} / \mathrm{km})$

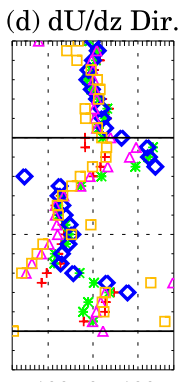

$\left({ }^{\circ}\right)$
The temporal evolution of these spatial features is summarized in Figures $2 \mathrm{~g}-2 \mathrm{n}$ as a function of $x$ (i.e., X-Time Doppler-Intensity, XTDI) (left) and $y$ (YTDI) (right) for selected altitudes. The extreme drafts are elongated along $y$ at all altitudes, and drift along $x$. At $89 \mathrm{~km}$, the updraft is observed to drift over the field of view at least $16-20 \mathrm{~km}$ in $x$, appearing around 04:20 and disappearing around 04:45 UT. The irregularities causing these echoes move up from around $86 \mathrm{~km}$ and stay at $89 \mathrm{~km}$ for at least $25 \mathrm{~min}$. At $81.5 \mathrm{~km}$, downdrafts are also elongated along the $y$ axis and drift generally along $x$. However, they are only observed for $2-4 \mathrm{~km}$ along $x$ and last less than $5 \mathrm{~min}$. The echoes at the lower altitudes are weaker and disappear after a few minutes. Later the echoes appear again around 04:55 due to irregularities coming from below and remain present at least until 05:30 UT. Both regions of updrafts and downdrafts drift at $\sim 11 \mathrm{~ms}^{-1}$ along $x$, North-East, with respect to an observer on the ground. Note that regions of large drafts are observed for a longer time in these plots than in the spectra plots in Figure 1, since the spectra were obtained using all 433 elements on transmission and reception. The duration, elongation, and horizontal extent of the event should be taken as minimum values, given the relatively small observing volume, when compared to other imaging observations (e.g., airglow imagers).

Figure 3 shows profiles of horizontal wind magnitude and direction as well as their vertical gradients. These profiles were obtained with the SMR described above, around the time of the event. A moderate horizontal wind shear $\left(24 \mathrm{~ms}^{-1} \mathrm{~km}^{-1}\right)$, occurs at the altitude where the extreme updrafts and downdrafts begin, that is, $86 \mathrm{~km}$. Recall that these are mean values representing an area of approximately $400 \mathrm{~km}$ diameter at $86 \mathrm{~km}$ obtained.

\section{Discussion}

The main features of the kilometer-scale extreme event presented here can be summarized as follows: (a) vertical drafts close to $5 \sigma_{w}$ occur during a limited time of $\sim 30$ min on July 16, 2016 around 04:30 UT; (b) they occur between 80 and $90 \mathrm{~km}$, (c) updrafts (downdrafts) up to 65 (45) $\mathrm{ms}^{-1}$ occur above (below) $86 \mathrm{~km}$, are observed for long (short) time, and their associated echoes present larger (smaller) SNR than echoes at $86 \mathrm{~km}$ where they begin; (d) it is localized in horizontal space with widths of $3-4 \mathrm{~km}$ in the $x$ axis, and elongated along the $y$ axis; (e) at the center altitude, the vertical gradient of the background horizontal wind is the largest $\left(24 \mathrm{~ms}^{-1} \mathrm{~km}^{-1}\right)$; (f) the PMSE layer thickness changes from $3 \mathrm{~km}$ (before the event) to $13 \mathrm{~km}$ (at the central time), (g) both drafts drift across the observing volume apparently against the mean horizontal wind at $\sim 11 \mathrm{~ms}^{-1}$, therefore the duration, elongation and horizontal extent of the event should be taken as minimum values.

\subsection{Verification of Our Observations}

Since our reported vertical velocities are not expected and might be controversial, in this section we summarize briefly some of the actions we have performed to verify the validity of our vertical velocity estimates. The first obvious check was range aliasing. Our unambiguous range is $300 \mathrm{~km}$, echoes coming from $380 \mathrm{~km}$ might be range aliased, however, their range, temporal, and spectral features do not correspond to such altitude. For example, if they were echoes from radar aurora, they would cover a much larger range (e.g., Chau $\&$ St.-Maurice, 2016). Moreover, plasma instabilities have been ruled out since (a) the ionosphere was quiet for a few hours around the event, and (b) the altitude is too low for plasma instabilities to be generated (e.g., St.-Maurice \& Chau, 2016). The former indicates that strong electric fields are not expected, while the latter is supported by high collision frequencies around $86 \mathrm{~km}$.

Horizontal velocity contamination is a usual suspect on vertical velocity studies, particularly when studying their mean values (e.g., Gudadze et al., 2019). As we mentioned above without considering radar imaging, unrealistic huge supersonic horizontal velocities would be needed to explain the reported vertical velocities. 


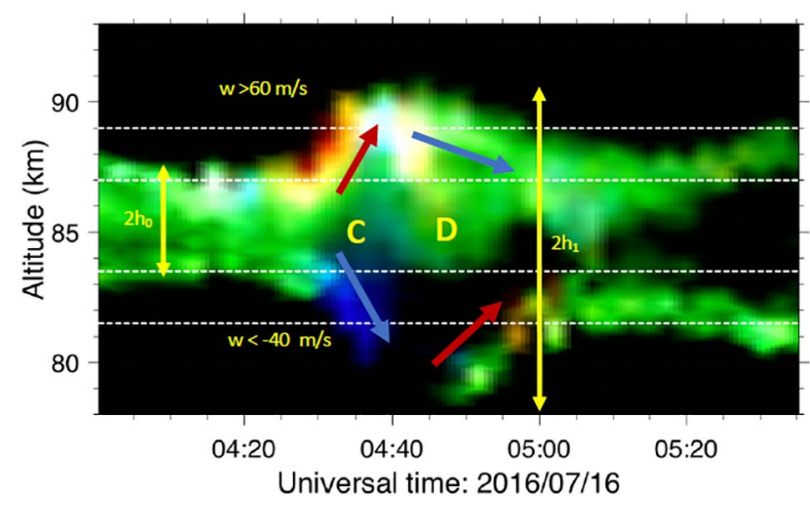

Figure 4. Closeup of the observations shown in Figure 1 to sketch the dynamics accompanying our event. The color code is the same as the one in Figure 2d. The regions of strong updraft (downdraft) are indicated with red (blue) arrows. Letter $\mathrm{C}$ and $\mathrm{D}$ represent horizontal wind convergence and divergence, respectively. Yellow vertical arrows indicate relevant vertical scales (see text).
Moreover in the imaging results, at a given altitude they would be shown with a transition from red to blue as the scattering center passes the beam center if the vertical velocity is very small. Figure $2 \mathrm{~g}$ clearly shows that the upper/lower altitude regions are red/blue as the event transits the beam. At most we expect the horizontal contamination to be within \pm 4 $\mathrm{ms}^{-1}$.

The vertical velocity profile is not constant at all altitudes at the central time of the event (i.e., 04:30), instead, it shows a maximum upward value around $89 \mathrm{~km}$, zero at $86 \mathrm{~km}$, and maximum downward value around $82 \mathrm{~km}$. If one assumes this vertical velocity profile to be constant for a few minutes, the resulting vertical displacement of a scattering region at $86 \mathrm{~km}$ is consistent with the observed vertical extent.

\subsection{Connection to Previous Mesospheric Observations}

A sketch based on the observations is shown in Figure 4. The SNR, vertical velocity, and spectral width from Figure 1 are combined into an altitude-time-Doppler intensity plot (e.g., Chau et al., 2020), with superimposed arrows indicating $w$ directions, and expected regions of horizontal wind convergence (C) and divergence (D) (see below). Our observed event resembles a solitary wave oscillating in varicose mode, that is, where the upper part is rising, the lower part is falling, and vice versa. This varicose mode is expected in internal bores (e.g., Dewan \& Picard, 2001) and has been directly observed in mesospheric bores (e.g., Fritts et al., 2020).

Our sketch together with the spatial features shown in Figure 2 resembles the mesospheric bore features of Bore 1 reported by Fritts et al. (2020), where they combined 2D images of PMC and lidar vertical profiling. As in the case of Fritts et al. (2020), we also expect that the observed vertical velocity divergence (convergence) ahead of (behind) the extreme event is accompanied by horizontal wind convergence (divergence). This horizontal wind behavior, unfortunately, could not be directly measured in our case. However, using vertical velocities from Figure 1i, the continuity equation and assuming an incompressible flow, the estimated local horizontal wind convergence is $\sim 14 \mathrm{~ms}^{-1} \mathrm{~km}^{-1}$, which is more than 100 times the measured mesoscale horizontal divergence in this region (Chau et al., 2017). This large local horizontal wind convergence/divergence is expected at the central altitude and not where the high vertical velocities are observed. Our assumption of incompressibility might not be totally correct given the high observed vertical velocities, possibly accompanied by local horizontal velocities larger than the speed of sound. Therefore, the estimated horizontal divergence/convergence values should be considered as upper values.

The vertical dimensions of our event are more than two times larger than those reported by Fritts et al. (2020), that is, $2 h_{1} \sim 13$ and $2 h_{0} \sim 3.0 \mathrm{~km}$, instead of 4.7 and $2.8 \mathrm{~km}$, respectively, where $2 h_{1}$ and $2 h_{0}$ are the vertical extensions during the peak of the perturbation and before the perturbation, respectively. These dimensions imply a normalized bore amplitude $\beta=\left(h_{1}-h_{0}\right) / h_{0} \sim 3.33$ which is much larger than previously measured or inferred characteristics of mesospheric bores or wall waves (e.g., Fritts et al., 2020; Li et al., 2007; Smith et al., 2003, 2017; Taylor et al., 1995). Vertical velocities in previous mesospheric bores have been expected or measured to be less than $10 \mathrm{~ms}^{-1}$ (e.g., Li et al., 2007).

Morphologically our extreme event resembles a mesospheric bore, but given its vertical dimensions, observed vertical velocities, and single observed crest, our event is unique. Unfortunately, temperature and density profiles are not available for this event. However, as in the case of typical mesospheric bores, we expect that our event is a consequence of an instability occurring in some type of ducting (Doppler, thermal, or a combination of both). Ducting regions are ubiquitous, but mesospheric bores are not. Possible mechanisms that have been invoked to explain mesospheric bores might also explain our observations, for example, interaction of gravity waves with the mean flow at a critical level (e.g., Dewan \& Picard, 1998), nonlinear internal gravity waves trapped within a thermal inversion layer (e.g., Seyler, 2005), and so on. Interesting to note is that run 8 in Seyler (2005, Table 1), reproduces a single-crest bore with larger amplitudes 
and Bore speeds than the other runs. However, none of the previous theories aimed to explain an event with the large $\beta$ and very high vertical velocities that characterized our observations.

DNS results of stratified flows have predicted extreme vertical velocities localized in space and time under particular values of stratification, specifically with Froude number $\sim 0.1-0.01$ (Feraco et al., 2018). Although a one-to-one comparison with our event is difficult, the DNS results indicate that the resonant interaction between gravity waves and turbulent motions responsible for the simulated DNS results, might play a role in explaining our event. Such comparison with DNS results and possibly more events will be pursued in future work.

\subsection{How Often Mesospheric Extreme Events Occur?}

We have presented only one event showing extreme vertical velocities. At this point, it is difficult to infer if this is an isolated one-of-a-kind event, or if they occur more often but, due to their high velocities and spatio-temporal characteristics, have been ignored.

In the case of previous PMSE observations with MAARSY, the great majority were done with Nyquist velocities less than $30 \mathrm{~ms}^{-1}$. Therefore, extreme drafts have been filtered out or were Doppler aliased, and cannot be recovered by their velocity values. In cases where larger Nyquist velocities have been used, they were presumably treated as outliers given their large values and relatively short duration (e.g., Gudadze et al., 2019, Figure 4). In the latter cases, a careful reprocessing should be pursued to search for additional extreme drafts. Data obtained with small Nyquist might still be useful, if one looks for sudden vertical excursions (up and down).

Mesospheric bores are not unique to the polar summer mesosphere and have been observed at other latitudes (Hozumi et al., 2019). If the observed extreme vertical velocities are indeed related to mesospheric bores one should search for extreme vertical velocities at other latitudes, seasons, with a variety of instruments. For example, mesospheric solitary waves (solitons) reported from foil chaff experiments in the past, might have sampled a small spatial and temporal portion of an extreme event like the one reported here (Widdel, 1991).

Although our work is focused on vertical velocities, such extreme events should show up in other atmospheric variables, for example, temperatures, airglow intensities, NLC brightness, and so on. As far as we know, extreme events based on these parameters have not been reported so far, or they might have been ignored.

\subsection{Potential Impacts}

In the particular case of the polar summer mesosphere, ice particles exist and they are the main reason for the presence of NLC and PMSE (e.g., Rapp \& Lübken, 2004; Thomas \& Olivero, 1986). Using expected temperature and pressure profiles from empirical models (e.g., Murphy \& Koop, 2005; Picone et al., 2002) as well as the observed vertical drafts, we find that in our specific case the temperature increases significantly in the downdraft regions. This increase causes the reduction of ice particle radius in time scales of a few minutes (see Figure S1). More details of these calculations can be found in the supplemental information. In the case of PMSE, their volume reflectivity is mainly determined by the Schmidt number, which is proportional to the square of ice particle radius (e.g., Rapp \& Lübken, 2004). Therefore a reduction of ice particle radius would mean a weaker PMSE. In Figure 1a, the strength of echoes decreases or echoes even disappears for the regions experiencing downdrafts. In the updraft regions, the strength of echoes increases but based on our calculations this increase is not related to the ice particle radius, instead it could be due to an increase in electron density. These simple calculations indicate that indeed ice particle radius is affected by extreme vertical drafts, and so are clouds and echoes relying on it.

As in the case of ice particles, other mesospheric species would also experience significant changes in altitude, and therefore their mixing ratios might change at a given altitude. The transport of photochemically inactive species across the turbopause by vertical winds enhances their concentration much more rapidly compared to turbulent mixing, which implies that extreme vertical updrafts are an effective mechanism to transport trace gases into the lower thermosphere. For example, if Argon and molecular Nitrogen are 
brought to higher altitudes, from 90 to $110 \mathrm{~km}$, it could take up to $3 \mathrm{~h}$ to fully mix these components, that is, much longer than if these species would have stayed at $90 \mathrm{~km}$ (e.g., Von Zahn et al., 1990).

\section{Conclusions}

We report the first observations of extreme vertical drafts $\left( \pm 50 \mathrm{~ms}^{-1}\right)$ in the mesosphere which show characteristics that resemble a solitary wave behavior in varicose mode. Although their horizontal and spatial structures resemble those of previously observed mesospheric bores, our event shows only one crest with a much larger vertical extent than previous observations.

Our current poor knowledge on these extreme drafts (formation, occurrence rate, duration, and predictability) as well as limited observing capabilities in the mesosphere, should not impede the exploration of impacts on other fields where kilometer-scale perturbations and instabilities and high vertical drafts might be important. If they occur frequently, a better understanding and characterization would contribute to the roles of kilometer-scale dynamics in a number of parameters requiring their parameterization in large-scale general circulation weather and climate models (e.g., Fritts et al., 2014, 2020). Further observations as well as theory and modeling efforts are still needed to find and identify the specific sources of our reported event.

\section{Data Availability Statement}

Open Research Data Statement PMSE radar spectra and imaging data as well as meteor wind data can be found here https://dx.doi.org/10.22000/396.

\section{Acknowledgments}

This study was partially supported by the Deutsche Forschungsgemeinschaft (German Research Foundation) under project LU1174/8-1 (PACOG) of the research unit FOR1898, and under SPP 1788 (CoSIP) project CH1482/31 (CS-PMSE-MIMO). R. Marino acknowledges support from the project "EVENTFUL" (ANR-20-CE30-0011), funded by the French "Agence Nationale de la Recherche"-ANR through the program AAPG-2020. The authors would like to thank Nikoloz Gudadze for suggesting us to look at the PMSE observations from July 16,2016 , and Dr. Miguel Larsen for his valuable suggestions. Open access funding enabled and organized by Projekt DEAL.

\section{References}

Adcock, T. A. A., \& Taylor, P. H. (2014). The physics of anomalous ('rogue') ocean waves. Reports on Progress in Physics, 77(10), 105901. https://doi.org/10.1088/0034-4885/77/10/105901

Chau, J. L., \& St-Maurice, J.-P. (2016). Unusual $5 \mathrm{~m}$ E region field-aligned irregularities observed from Northern Germany during the magnetic storm of 17 March 2015. Journal of Geophysical Research: Space Physics, 121(10), 310-316. https://doi.org/10.1002/2016ja023104

Chau, J. L., Stober, G., Hall, C. M., Tsutsumi, M., Laskar, F. I., \& Hoffmann, P. (2017). Polar mesospheric horizontal divergence and relative vorticity measurements using multiple specular meteor radars. Radio Science, 52(7), 811-828. https://doi.org/10.1002/2016RS006225

Chau, J. L., Strelnikova, I., Schult, C., Oppenheim, M. M., Kelley, M. C., Stober, G., \& Singer, W. (2014). Nonspecular meteor trails from nonfield-aligned irregularities: Can they be explained by presence of charged meteor dust? Geophysical Research Letters, 41(10), 3336-3343. https://doi.org/10.1002/2014GL059922

Chau, J. L., Urco, J. M., Avsarkisov, V., Vierinen, J. P., Latteck, R., Hall, C. M., \& Tsutsumi, M. (2020). Four-dimensional quantification of Kelvin-Helmholtz instabilities in the polar summer mesosphere using volumetric radar imaging. Geophysical Research Letters, 47(1), D09S12. https://doi.org/10.1029/2019GL086081

Dewan, E. M., \& Picard, R. H. (1998). Mesospheric bores. Journal of Geophysical Research, 103(D6), 6295-6305. https://doi. org/10.1029/97jd02498

Dewan, E. M., \& Picard, R. H. (2001). On the origin of mesospheric bores. Journal of Geophysical Research, 106, 2921-2927. https://doi. org/10.1029/2000JD900697

Ecklund, W. L., \& Balsley, B. B. (1981). Long-term observations of the Arctic mesosphere with the MST radar at Poker Flat, Alaska. Journal of Geophysical Research, 86, 7775-7780. https://doi.org/10.1029/JA086iA09p07775

Feraco, F., Marino, R., Pumir, A., Primavera, L., Mininni, P. D., Pouquet, A., \& Rosenberg, D. (2018). Vertical drafts and mixing in stratified turbulence: Sharp transition with Froude number. Europhysics Letters, 123(4), 44002. https://doi.org/10.1209/0295-5075/123/44002

Fritts, D. C., Baumgarten, G., Wan, K., Werne, J., \& Lund, T. (2014). Quantifying Kelvin-Helmholtz instability dynamics observed in noctilucent clouds: 2. Modeling and interpretation of observations. Journal of Geophysical Research: Atmospheres, 119(15), 9359-9375. https://doi.org/10.1002/2014JD021833

Fritts, D. C., Kaifler, N., Kaifler, B., Geach, C., Kjellstrand, C. B., Williams, B. P., et al. (2020). Mesospheric bore evolution and instability dynamics observed in PMC Turbo imaging and Rayleigh Lidar profiling over Northeastern Canada on 13 July 2018. Journal of Geophysical Research: Atmospheres, 125, e2019JD032037. https://doi.org/10.1029/2019JD032037

Fritts, D. C., Williams, B. P., She, C. Y., Vance, J. D., Rapp, M., Lübken, F. J., \& Goldberg, R. A. (2004). Observations of extreme temperature and wind gradients near the summer mesopause during the MaCWAVE/MIDAS rocket campaign. Geophysical Research Letters, 31, L24S06. https://doi.org/10.1029/2003GL019389

Gardner, C. S., \& Liu, A. Z. (2007). Seasonal variations of the vertical fluxes of heat and horizontal momentum in the mesopause region at Starfire Optical Range, New Mexico. Journal of Geophysical Research, 112, D09113. https://doi.org/10.1029/2005JD006179

Gardner, C. S., Tao, X., \& Papen, G. C. (1995). Simultaneous lidar observations of vertical wind, temperature, and density profiles in the upper mesophere: Evidence for nonseparability of atmospheric perturbation spectra. Geophysical Research Letters, 22, 2877-2880. https:// doi.org/10.1029/95GL02783

Gudadze, N., Stober, G., \& Chau, J. L. (2019). Can VHF radars at polar latitudes measure mean vertical winds in the presence of PMSE? Atmospheric Chemistry and Physics, 19(7), 4485-4497. https://doi.org/10.5194/acp-19-4485-2019

Herbert, C., Marino, R., Rosenberg, D., \& Pouquet, A. (2016). Waves and vortices in the inverse cascade regime of stratified turbulence with or without rotation. Journal of Fluid Mechanics, 806, 165-204. https://doi.org/10.1017/JFM.2016.581

Hocking, W. K., Fuller, B., \& Vandepeer, B. (2001). Real-time determination of meteor-related parameters utilizing modern digital technology. Journal of Atmospheric and Solar-Terrestrial Physics, 63(2), 155-169. https://doi.org/10.1016/s1364-6826(00)00138-3 
Hoppe, U.-P., \& Fritts, D. C. (1995). High-resolution measurements of vertical velocity with the European incoherent scatter VHF radar: 1. Motion field characteristics and measurement biases. Journal of Geophysical Research, 100(D8), 16813-16825. https://doi. org/10.1029/95JD01466

Hoppe, U.-P., Hall, C., \& Röttger, J. (1988). First observations of summer polar mesospheric backscatter with a $224 \mathrm{MHz}$ radar. Geophysical Research Letters, 15(1), 28-31. https://doi.org/10.1029/GL015i001p00028

Hozumi, Y., Saito, A., Sakanoi, T., Yamazaki, A., Hosokawa, K., \& Nakamura, T. (2019). Geographical and seasonal variability of mesospheric bores observed from the International Space Station. Journal of Geophysical Research: Space Physics, 124(5), 3775-3785. https:// doi.org/10.1029/2019JA026635

Hysell, D. L., \& Chau, J. L.(2006). Optimal aperture synthesis radarimaging. Radio Science, 41, RS2003.https://doi.org/10.1029/2005RS003383

Larsen, M. F., \& Meriwether, J. W. (2012). Vertical winds in the thermosphere. Journal of Geophysical Research, 117(9), A09319. https:// doi.org/10.1029/2012JA017843

Latteck, R., Singer, W., Rapp, M., Vandepeer, B., Renkwitz, T., Zecha, M., \& Stober, G. (2012). MAARSY: The new MST radar on AndøyaSystem description and first results. Radio Science, 47(1), RS1006. https://doi.org/10.1029/2011RS004775

Lehmacher, G. A., Scott, T. D., Larsen, M. F., Bilén, S. G., Croskey, C. L., Mitchell, J. D., et al. (2011). The Turbopause experiment: Atmospheric stability and turbulent structure spanning the turbopause altitude. Annales Geophysicae, 29, 2327-2339. https://doi.org/10.5194/ angeo-29-2327-2011

Li, F., Swenson, G. R., Liu, A. Z., Taylor, M., \& Zhao, Y. (2007). Investigation of a "wall” wave event. Journal of Geophysical Research, 112(D4), D04104. https://doi.org/10.1029/2006JD007213

Lübken, F.-J., Jarvis, M. J., \& Jones, G. O. L. (1999). First in situ temperature measurements at the Antarctic summer mesopause. Geophysical Research Letters, 26(24), 3581-3584. https://doi.org/10.1029/1999GL010719

Marino, R., Rosenberg, D., Herbert, C., \& Pouquet, A. (2015). Interplay of waves and eddies in rotating stratified turbulence and the link with kinetic-potential energy partition. Europhysics Letters, 112(4), 49001. https://doi.org/10.1209/0295-5075/112/49001

Murphy, D. M., \& Koop, T. (2005). Review of the vapour pressures of ice and supercooled water for atmospheric applications. Quarterly Journal of the Royal Meteorological Society, 131, 1539-1565. https://doi.org/10.1256/qj.04.94

Picone, J. M., Hedin, A. E., Drob, D. P., \& Aikin, A. C. (2002). NRLMSISE-00 empirical model of the atmosphere: Statistical comparisons and scientific issues. Journal of Geophysical Research, 107(A12), SIA151-SIA1516. https://doi.org/10.1029/2002JA009430

Pouquet, A., Marino, R., Mininni, P. D., \& Rosenberg, D. (2017). Dual constant-flux energy cascades to both large scales and small scales. Physics of Fluids, 29(11), 111108. https://doi.org/10.1063/1.5000730

Rapp, M., \& Lübken, F.-J. (2004). Polar mesosphere summer echoes (PMSE): Review of observations and current understanding. Atmospheric Chemistry and Physics, 4, 2601-2633. https://doi.org/10.5194/acp-4-2601-2004

Sato, K., Kohma, M., Tsutsumi, M., \& Sato, T. (2017). Frequency spectra and vertical profiles of wind fluctuations in the summer Antarctic mesosphere revealed by MST radar observations. Journal of Geophysical Research: Atmospheres, 122(1), 3-19. https://doi. org/10.1002/2016JD025834

Seyler, C. E. (2005). Internal waves and undular bores in mesospheric inversion layers. Journal of Geophysical Research, $110(\mathrm{D} 9)$, D09S05. https://doi.org/10.1029/2004jd004685

Smith, S. M., Stober, G., Jacobi, C., Chau, J. L., Gerding, M., Mlynczak, M. G., et al. (2017). Characterization of a double mesospheric bore over Europe. Journal of Geophysical Research: Space Physics, 122(9), 9738-9750. https://doi.org/10.1002/2017JA024225

Smith, S. M., Taylor, M. J., Swenson, G. R., She, C. Y., Hocking, W., Baumgardner, J., \& Mendillo, M. (2003). A multidiagnostic investigation of the mesospheric bore phenomenon. Journal of Geophysical Research, 108(A2), 1-18. https://doi.org/10.1029/2002JA009500

St-Maurice, J.-P., \& Chau, J. L. (2016). A theoretical framework for the changing spectral properties of meter-scale Farley-Buneman waves between 90 and $125 \mathrm{~km}$ altitudes. Journal of Geophysical Research: Space Physics, 121(10), 310-341. https://doi.org/10.1002/2016ja023105

Taylor, M. J., Turnbull, D. N., \& Lowe, R. P. (1995). Spectrometric and imaging measurements of a spectacular gravity wave event observed during the ALOHA-93 Campaign. Geophysical Research Letters, 22(20), 2849-2852. https://doi.org/10.1029/95GL02948

Thomas, G. E., \& Olivero, J. J. (1986). The heights of polar mesospheric clouds. Geophysical Research Letters, 13(13), 1403-1406. https:// doi.org/10.1029/GL013i013p01403

Tippett, M. K., \& Cohen, J. E. (2016). Tornado outbreak variability follows Taylor's power law of fluctuation scaling and increases dramatically with severity. Nature Communications, 7, 10668. https://doi.org/10.1038/ncomms10668

Urco, J. M., Chau, J. L., Weber, T., \& Latteck, R. (2019). Enhancing the spatio-temporal features of polar mesosphere summer echoes using coherent MIMO and radar imaging at MAARSY. Atmospheric Measurement Techniques, 12, 955-969. https://doi.org/10.5194/ amt-12-955-2019

Von Zahn, U., Lübken, F. J., \& Putz, C. (1990). BUGATTI experiments: Mass spectrometric studies of lower thermosphere eddy mixing and turbulence. Journal of Geophysical Research, 95(D6), 7443-7465. https://doi.org/10.1029/JD095iD06p07443

Widdel, H.-U. (1991). Experimental evidence for solitary waves in the middle atmosphere. Journal of Geophysical Research, 96(A9), 1593115942. https://doi.org/10.1029/91ja01396

Woodman, R. F., \& Guillén, A. (1974). Radar observations of winds and turbulence in the stratosphere and mesosphere. Journal of the Atmospheric Sciences, 31(2), 493-505. https://doi.org/10.1175/1520-0469(1974)031<0493:roowat>2.0.co;2 